\title{
Research on the Public Space Reconstruction of the Old Community in the Historical and Cultural District
}

\author{
Rui DING ${ }^{\text {a }}$, Hong XU ${ }^{\text {a,1 }}$ and Jing HUANG ${ }^{\text {a }}$ \\ ${ }^{a}$ School of Urban Construction, Wuhan University of Science and Technology, Wuhan, \\ China
}

\begin{abstract}
With the rapid development of urbanization, urban planning will inevitably be accompanied by discussions on the transformation of old communities. How to integrate and develop the transformation of old communities with the renewal and protection of historical and cultural blocks is also the object of our research. Regarding the creation of the atmosphere of the public space in the old quarters in the historical and cultural blocks, it is the inheritance of the historical context in the urban planning. Taking the transformation of Wuhan Tanhualin community as an example, based on the theory of urban acupuncture and moxibustion, this article discusses the planning strategy of how to solve the public space transformation of old communities in historical and cultural districts at multiple levels and multiple dimensions. Conduct public space analysis and public life surveys on old communities through literature analysis and field research methods, put forward strategies for the transformation of old communities in emergent public health safety incidents, and advocate low-impact development construction methods to realize the old community areas Sustainable development. When dealing with the connection between the new and the old space, it can establish a visual dialogue relationship between the new and the old space, and at the same time establish the historical and humanistic resonance effect between the public space and the historical and cultural block. Create an old community public space with historical and cultural characteristics, green and safe coordination.
\end{abstract}

Keywords. Historical and cultural blocks, reconstruction of old communities, public space, Urban Acupuncture Theory

\section{Introduction}

With the rapid development of society, the transformation of old communities has become increasingly popular, and for the transformation of old communities, on July 20, 2020, the General Office of the State Council issued the "Guiding Opinions", put forward opinions for comprehensively promoting the transformation of old communities in cities and towns. For the research on the transformation of old communities in historical and cultural blocks, while focusing on improving and solving the basic needs of residents in the community, it is necessary to pay more attention to the inheritance and continuation of its historical culture. This article explores the key

\footnotetext{
${ }^{1}$ Hong Xu, School of Urban Construction, Wuhan University of Science and Technology, Wuhan, China; E-mail: xuhong@wust.edu.cn.
} 
points of public space reconstruction in old communities in historical and cultural districts through literature analysis and field research methods.

\section{Research Background}

\subsection{Research Background and Concept Definition of Urban Acupuncture and Moxibustion Theory}

\subsubsection{Urban Acupuncture}

Urban acupuncture is a small-scale, gradual urban renewal proposed by Spanish urban architect Manuel de Sola Morales under the background of the implementation of the Barcelona urban relaunch plan in the 1980s. Strategy. [1] It can be understood that in the process of urban renewal, we can use a specific point area to update small-scale public space, so that the public space has a certain effect and can drive the change of the surrounding overall environment. So as to finally achieve the overall urban renewal and stimulate the vitality of the city. It can be understood as an urban renewal that uses the smallest scale of transformation to achieve the greatest effect.

And the theory of "urban acupuncture" has been widely used, such as Zhang Yu's "Research on Rural Space Renewal Strategy Based on Urban Acupuncture Theory" proposed by Zhang Yu to construct a unified overall spatial form with three elements, channel the traffic network, and build street space [2] ; For example, Cheng Xin applied it to the research of campus space renewal in "Urban Acupuncture and Moxibustion" in "Urban Acupuncture and Moxibustion" Perspective: Taking University Campuses in Kunming as an Example [3]; such as Zhou Haiyang in "Urban Acupuncture and Moxibustion" "The Application in the Spatial Reconstruction of General Historical Towns-Taking the Spatial Reconstruction of the Ancient City of Yaozhou as an Example" proposes a method for the spatial transformation of general historical towns [4]. For example, Wen Chao, Yang Xinhai, Wen Jiangang and Shi Huinan provided new ideas for solving the problem of urban village renewal in the article "Inquiry into the Organic Renewal Mode of Urban Villages Based on "Urban Acupuncture and Moxibustion"'" [5].

\subsubsection{Definition of Concept}

From the perspective of the research content, the relevant literature on urban acupuncture has been sorted out. It is not difficult to find that although different scholars have their own understanding of the definition and understanding of the concept of urban acupuncture, they have basically reached a consensus. As Zhang Xiao mentioned in the article "A Brief Talk on "Urban Acupuncture"", "it makes small-scale transformations in a specific area by means of "point-cutting" to trigger its surrounding environment. The changes in the city ultimately serve the purpose of stimulating the vitality of the city, changing the appearance of the city, and renewing the city" [6]. For example, Sun Qian, Li Wen and $\mathrm{Hu}$ Zhongjun mentioned in the article "Urban Acupuncture Guided by Public Centers" that in some specific areas, Use small-scale access to public centers to stimulate the development of surrounding areas and promote the renewal of the entire area [7]. For example, Chu Dongzhu proposed in the article "A Preliminary Study on Architectural Strategies under the Concept of "Urban Acupuncture and Moxibustion" "Architecture and Transportation Integration", 
"Acupuncture" can be applied to the system and complexity of "traffic problems". Point (moxibustion point) to achieve overall optimization-scholars call it the 'moxibustion point strategy' " [8].

\subsection{The Difference between Urban Acupuncture and urBan Catalyst}

When it comes to "urban acupuncture", we think of "urban catalyst". For example, the difference between the two is that "urban catalysts" refer to those that can promote changes in the city, which can make a certain change in the development and construction of the city. And this kind of "urban catalyst" is not a single final product, but an element that can stimulate and guide urban development and construction [7] What "urban acupuncture" wants to express is to intervene in the development of urban construction in a small-scale intervention mode, so as to achieve the effect of revitalizing the neighborhood [9].

\section{Reconstruction of Public Space in Old Quarters in Historical and Cultural Blocks}

\subsection{The Historical and Humanistic Resonance Effect between the Public Space of the Old Community and the Historical and Cultural Block}

In the course of urban development, different environments and different regions have different characteristics of regional culture and urban style, and the public spaces of old communities have also exposed various problems, and the public spaces of old communities in a certain area The renovation and transformation of the city not only needs to optimize the basic life needs, but also needs to meet the unique historical and humanistic spirit of its region. To make the two have a resonance effect, on the one hand, it can meet the rigid needs of people's physiological needs, but also can meet the pursuit of people's psychological needs. On the other hand, it forms a unified and complete construction to achieve sustainable and circular development in the true sense.

\subsection{The Status Quo of Public Space Renovation in Old Communities}

Some old communities have visual collisions due to the relatively long construction period or different construction times in the same area, and they will be accompanied by incomplete basic service facilities in public spaces, low quality of built-in landscapes in public spaces, and chaotic design elements Other issues have adversely affected the lives of local residents.

\section{Analysis on the Current Situation of Public Space in Wuhan Tanhualin Area}

\subsection{District Analysis}

Wuhan Tanhualin is located in Wuchang District, Wuhan City, between Linjiang Avenue and Crab Point. In 1946, the local authorities merged Zhengwei Street west of the Gejiaying exit, Youjiaxiang and Tan Hualin east of the Gejiaying exit, collectively 
referred to as Tan Hualin, and it is still used today. The narrow strip includes Gejiaying, Madaomen, Taiping Examination Hall, Sanyi Village, and Huayuan Mountain and Crab Cape. The selected location in Tanhualin area is relatively excellent in humanistic environment, rich in educational resources, and rich in historical environment. There are 52 historical buildings in Tanhualin area, such as the former residence of Shi Ying. The transportation routes here are well developed and the geographical position is superior [10]. This article will analyze and discuss the public space of Madaomen Community in Tanhualin Community of Liangdao Street in Tanhualin District of Wuhan (figure 1).

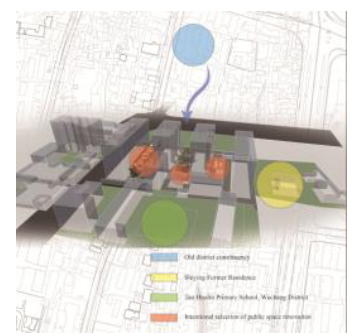

Figure 1. Old district reconstruction constituency.

\subsection{Current status of Traffic Space}

Through field research, it is found that the overall traffic route and parking situation within Madaomen District are in a rather messy plan. The entrance of Madaomen Community is located on the side of the main road of Tanhualin Historical and Cultural District. It is close to the street . Its internal traffic route is single, and the internal space of the community is narrow. State, and the fire passage is heavily occupied, there are a lot of hidden safety hazards. And in the designated parking area of the community, the parking needs of residents cannot be met, so that the vehicles can be seen everywhere on the sidewalk (figure 2).

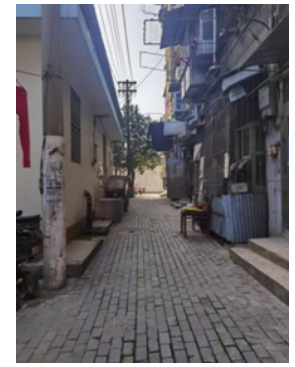

Figure 2. Internal roads of Madaomen Community.

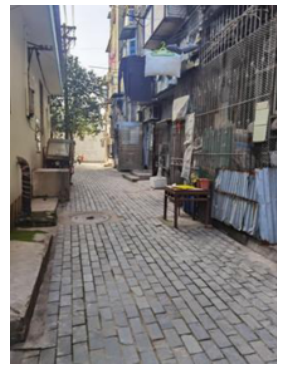

Figure 3. Map of the status quo of Madaomen District.

\subsection{Culture Current Status of Community Public Facilities}

Due to the small public space in the old community in Wuhan Tanhualin area, residents here can carry out daily activities in the only public space. Due to the old building, 
many residents spontaneously renovate the building and extend the space outside the house. Resulting in hidden dangers to life safety. Community public facilities are the most basic manifestation of whether the entire public space is qualified. Through field research, it is found that because the buildings are relatively close and the gap between the building and the building is narrow, the residents of the community do not have an open public space. The interior of the Madaomen community The space for communication is relatively scarce, and public infrastructure is lacking (figure 3).

\subsection{Discussion on the Connection of New and Old Spaces}

When transforming the public space of an old community in a historical and cultural block, it will inevitably be faced with the connection between the new space and the old space, and the gray space in this situation will also exist within the scope of the public space. Here, the "new space" "And "old space" respectively refer to the spatial contrast of the public space of buildings or structures built at different time periods, and the gray space in the new and old space refers to the optimization and improvement of the public space of the old community The space of "new space" and "old space" have a seemingly unrelated connection before, and the "gray space" from it is its medium. Using the related theories of "Urban Acupuncture" as the core point of public space transformation, using this small-scale gradual transformation, the gray space transformation can give full play to the greatest benefits.

\section{Thoughts and Suggestions on the Public Space Reconstruction of the Old Community in Wuhan Tanhualin Area under the Theory of "Urban Acupuncture and Moxibustion"}

\subsection{Responding to the Spatial Function Layout in Public Health Safety}

With the continuous development and change of the new crown pneumonia epidemic at home and abroad, the community has become the first line of defense for epidemic prevention and control and virus tracking, and the old community facing transformation should pay more attention to the spatial layout of public space. Looking to the future, we must pay more attention to public health safety, and the community, as the first front of public health safety prevention and control, should be more spatially planned. The public space of the old community is an interactive open public place between buildings. Based on the study of the theory of "urban acupuncture and moxibustion", taking the Madaomen community of Tanhualin community as an example, it can be transformed in a point manner. To affect the surrounding environment.

\subsection{Reasonably Create a Transitional Public Space between the New and the Old Space}

First of all, we need to improve the supporting facilities and infrastructure. Optimize and transform the internal infrastructure of the community. The first is to repair damaged building facades, community roads, etc. inside the community. The second is to increase basic public facilities in the community, such as street lights, trash cans, etc. 
The addition of a large number of public service facilities in the public space of Tanhualin Community can increase the feelings among residents in the community, thereby making the whole community full of happiness. When carrying out small-scale public space renovation, attention should be paid to diversified designs for the needs of different groups of people. In short, it is to improve the infrastructure of public space according to the needs of different groups of people.

Second, we need to make full use of space. Make full use of the space inside the community to create a three-dimensional public activity space with rich levels. In the renovation design of the community, because the public space of Madaomen community is relatively small and the public space is relatively crowded as a whole, in order to create more social space, the design method of "container" as the prototype of the space design can be fully adopted. Solve the problem of people flowing and staying in the community; and it can also make it one of the important places for the residents of the community to live activities. At the same time, this also creates a reasonable public space between the new and the old space (figure 4).

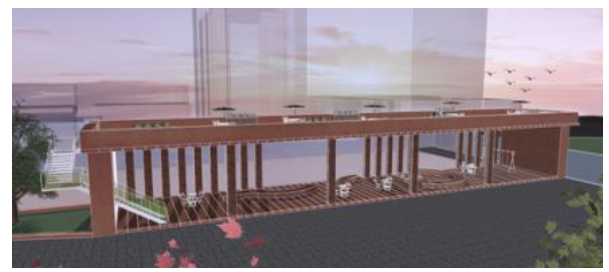

Figure 4. Event venue effect picture.

\subsection{Improve and Optimize the Greening Atmosphere in the Public Space of the Community}

At the same time, we must improve and optimize the greening of the community's public space, rationally design and plan green areas within the community, and carry out greening design on the internal main roads of the community, so as to improve the current status of greening within the community. According to the field survey, we found that the Madaomen community in Tanhualin area has almost zero greening due to the small public space. Only some green plants planted in flowerpots serve as the greening of the community, so we can A green space is designed between the two buildings, and greening and public leisure facilities are interspersed on the original foundation. This not only creates a green atmosphere inside the community, but also creates a place for community residents to exchange activities (figure 5).

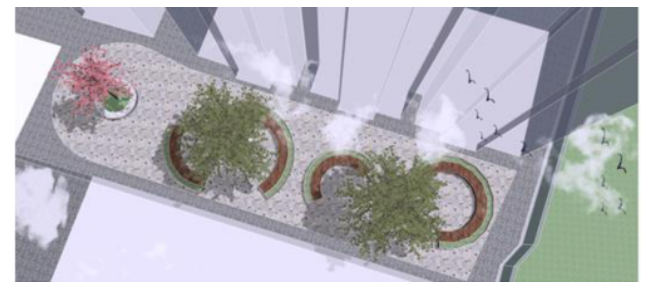

Figure 5. Public green space design. 


\section{Conclusion}

Based on the analysis of the public space in the Zhongmadaomen district in the Tanhualin area of Wuhan, this article uses "urban acupuncture" to consider the strategy research of the public space transformation of the old community in the historical and cultural block. The research object is more and more expanded. Laiyue pays more attention to the particularity and unity of various local historical and cultural buildings and locations, and can establish a resonance effect between public space and historical districts. Promoting and inheriting history and culture is the goal we are pursuing. If only the lack of functions is singularized and modularized, it will cause serious harm to the development of the entire city's culture. Civilization is the essence and soul of this city, so when we need to carry out spatial transformation, we must always pay attention to the inheritance and continuation of history and culture.

\section{Acknowledgments}

This works was financially supported by the National Natural Science Foundation of China(Grants\#41771473), Key research projects of philosophy and social sciences of Hubei Provincial Department of Education (Grants\#20D025).

\section{References}

[1] Jia YD, Guo Q. Research and analysis of urban acupuncture theory. Chinese and Foreign Architecture. 2021 Mar; (03): 86-91.

[2] Zhang Y. Research on rural spatial renewal strategy based on urban acupuncture theory. Ju She. 2018 Nov; (31): 96+132.

[3] Cheng X. Research on the micro-renewal design of university campus space based on the vision of "urban acupuncture". Kunming University of Science and Technology; 2020.

[4] Zhou HY. The application of "urban acupuncture" in the spatial transformation of general historical towns: Taking the spatial transformation of the ancient city of Yaozhou as an example. Technological Innovation and Productivity. 2015 Sept; (09): 10-12+15.

[5] Wen C, Yang XH, Wen JG, Shi HN. Research on the organic renewal model of urban villages based on "urban acupuncture". Urban Development Research. 2017 Nov; 24(11): 43-50.

[6] Zhang X. Talking about "urban acupuncture" Huazhong Architecture. 2012 Oct; 30(10): 23-25.

[7] Sun Q, Li W, Hu ZJ. Urban acupuncture guided by public center. Chinese and Foreign Architecture. 2010 Dec; (12): 100-101.

[8] Chu DZ. Urban acupuncture and moxibustion: preliminary exploration of architectural strategy under the concept of "integration of architecture and transportation". New Architecture. 2011 Jun; (03): 39-44.

[9] Zhu XY, Liu YY, Lan SR, Huang QT. The activation and renewal strategy of Nanjie block in Fuzhou based on urban catalyst theory. China Urban Forestry. 2020 Dec; 18(06): 89-94.

[10] Liao X, Xiao X. Discussion on the spatial relationship between Wuhan residents' lifestyle and urban public activity landscape. Chinese and Foreign Architecture. 2016 Jul; (07): 41-44. 